\title{
0 agenda-setting no Brasil: contradições entre o sucesso e os limites epistemológicos
}

\section{Kênia Beatriz Ferreira Maia e Luciane Fassarella Agnez}

\section{Resumo}

Com a efervescência dos estudos em jornalismo, as constantes críticas e os sucessivos esforços de se delimitar epistemológica e metodologicamente a área, o presente artigo coloca em discussão os trabalhos sobre 0 agenda-setting, ou do agendamento da mídia, questionando o sucesso que a abordagem alcançou nacionalmente. A partir de uma análise empírica, com base em papers apresentados nos principais fóruns das ciências da comunicação no Brasil, examinamos como essa tradição é reapropriada pelos pesquisadores brasileiros, quais as metodologias usadas e se há acúmulo de conhecimento.

\section{Palavras-chave:}

Agenda-setting. Teoria do Jornalismo. Epistemologia da Comunicação.
Kênia Beatriz Ferreira Maial keniamaia@yahoo.com Doutora em Ciência da Informação e da Comunicação, Universidade Paul Verlaine-Metz (França). Professora do Departamento de Comunicação da UFRN e do Programa de Pós-graduação em Estudos de Mídia, da UFRN.

Luciane Fassarella Agnez | luagnez@gmail.com Mestranda do Programa de Pós-graduação em Estudos da Mídia pela UFRN.

\section{Introdução}

Os estudos em jornalismo são bastante florescentes no Brasil. Somente a Divisão Temática (DT) "Jornalismo" da Sociedade Brasileira de Estudos Interdisciplinares da Comunicação (Intercom) apresenta cinco Grupos de Pesquisa (GP), que abrangem gêneros, história, jornalismo impresso, telejornalismo e teoria do jornalismo. Em 2009, durante o Congresso da Intercom, essa DT reuniu mais de 170 trabalhos de pesquisadores de todo o país. Desde a criação da Associação Brasileira de Pesquisadores em Jornalismo (SBPJor), os eventos anuais da entidade recebem um número crescente de papers. No primeiro encontro da entidade, em 2003, foram apresentados cerca de 50 artigos, distribuídos em Comunicação Individual e Comunicação Coordenada. No ano passado, esse número chegou a mais de 150. 0 Grupo de Trabalho (GT) de Estudos do Jornalismo foi renovado pelo processo de reciclagem da Associação Nacional dos Programas de Pós-graduação em Comunicação (Compós) e completa 11 
anos. Sem contar os diversos periódicos científicos da área da comunicação, como as revistas Ícone (UFPE), Contemporânea (UERJ), Em Questão (UFRGS) e a própria E-Compós, que dedicam dossiês recentes ao jornalismo. Esse fôlego duradouro pode ocultar outras realidades. Os estudos de jornalismo ainda carecem de legitimidade. De um lado, constantes são as críticas ao campo (MARTINO, 2007; SILVA, 2009); de outro, há defesas da existência do jornalismo enquanto de um campo de conhecimento específico (MACHAD0, 2004).

Essa discussão epistemológica é profícua e necessária. Entretanto, este espaço não tem a pretensão nem a intenção de se debruçar sobre ela, mas sim de constatar determinadas fragilidades de alguns estudos de jornalismo. A partir da análise de 34 trabalhos sobre agendasetting e agendamento, vamos examinar como essa tradição de pesquisa é reapropriada pelos brasileiros e quais as metodologias usadas em artigos que reivindicam dessa tradição e se há um acúmulo de conhecimento. A escolha pelo tema do agenda-setting se deve principalmente pelo grande número de trabalhos utilizando esse conceito ou citando os escritos de Maxwell McCombs e Donald Shaw no Brasil, apesar de vários estudos de autores de outras nacionalidades relativizarem essas pesquisas, destacando suas debilidades teóricas e metodológicas (CHARRON, 1995; WOLF, 1999).

\section{Percurso dos estudos sobre agenda-setting}

Neste trabalho, não pretendemos tardar na descrição da evolução das pesquisas sobre 0 agenda-setting. Vários autores já debruçaram sobre isso, inclusive os próprios conceituadores (McCOMBS; SHAW, 2000b) e outros analistas (BARROS FILHO, 1995; HOHLFELDT, 1997; WOLF, 1999; TRAQUINA, 2000). Faz-se, contudo, necessário traçar uma mínima contextualização. Afinal, pairam inúmeras dúvidas sobre a ontologia e o estatuto epistemológico do tema. Conforme 0 autor, 0 agenda-setting é designado como teoria, hipótese, linha de pesquisas, metodologia, conceito ou conceito guarda-chuva. Além disso, Traquina (2000) traduz o "agendasetting" por "agendamento". Ao fazê-lo, ignora 0 verbo "set". Ora, outras tradições de pesquisas acrescentam palavras diferente ao termo "agenda", como por exemplo "agenda-building" (NISBET, 2008) para descrever e analisar um fenômeno distinto do agenda-setting. Para demarcar que estamos nos referindo especificamente a uma determinada tradição de estudos, novamente optamos por utilizar somente o termo agenda-setting, ou a sigla "AS".

0 agenda-setting se insere na tradição funcionalista dos estudos norte-americanos em comunicação, que tem como ponto nodal a análise e detecção das funções e dos efeitos causados pelos meios de comunicação sobre a audiência, tradição que é designada por alguns 
autores como mass communication research (WOLF, 1999). Mas essa categorização não é consensual. Para discutir a filiação teórica, Colling (2001) se propõe a desatar o emaranhado acerca da posição do agenda-setting em relação à tradição norte-americana dos efeitos limitados, analisando os postulados de Traquina (2000), segundo o qual o AS demonstra os efeitos poderosos da mídia da informação. Além disso, coloca-o em perspectiva com McCombs e Shaw, que preferem enquadrá-lo como pertencendo à teoria dos efeitos indiretos ou limitados, igualmente da tradição funcionalista, na qual Mattelart e Mattelart (1995) categorizam 0 agenda-setting. Assim, em que pese 0 AS ser ou não uma retomada ou uma superação das pesquisas dos efeitos limitados, o importante é que se inscreve nas pesquisas dos "efeitos". Entretanto, num livro sob sua organização que traz 0 artigo fundador e outros trabalhos subsequentes, Traquina (2000) correlaciona o AS com a perspectiva teórica da construção social da realidade, também designada construcionismo, a partir do processo de produção da notícia. Trabalhos que se subsidiaram exclusivamente na obra de Traquina para traçar o histórico desses estudos vão situar $0 \mathrm{AS}$ na teoria construcionista (MAZZARINO, 2007).

A atração que a tradição funcionalista exerce sobre os pesquisadores em comunicação é visível e se assemelha a um movimento pendular que traz o constante retorno da questão do "efeito" da mídia sobre as pessoas. Um exemplo é Traquina (2000) com o seu artigo "A redescoberta do poder do jornalismo: análise da teoria do agendamento". Talvez seja essa a razão do sucesso do AS no Brasil: McCombs e Shaw criam os assentos teóricos para subsidiar os trabalhos acadêmicos que propagam o poder (influência) do jornalismo. 0 suposto poder atribuído aos meios de comunicação não é uma ideia nova - e já não era à época dos primeiros trabalhos sobre 0 agenda-setting. No artigo inaugural do AS, McCombs e Shaw (2000a) declaram que se inspiram em Walter Lippmann e Bernard Cohen. O jornalista Walter Lippmann, com o livro Public Opinion, de 1922, defendeu que os meios de comunicação exerciam um importante papel na mediação dos cidadãos com o mundo real, para a apreensão de fatos e ideologias necessários à formação de uma opinião pública. Na década de 1960, Bernard Cohen já havia formulado de forma mais sucinta a questão do agendamento da mídia, alertando para a eficácia da imprensa em indicar aos leitores "sobre o que pensar". McCombs e Shaw (2000a) atribuíram um conceito a esse fenômeno e conseguiram sistematizar a hipótese de que os media poderiam agendar as temáticas junto à opinião pública e ainda determinar uma hierarquia de relevância entre os acontecimentos.

0 agenda-setting surgiu como uma hipótese, a ser testada, e não como uma teoria fechada. Depois dos primeiros estudos, realizados nas eleições presidenciais americanas de 1968 e no caso Watergate, em 1973, os autores estimam que duas centenas de artigos foram produzidos sobre a temática somente nas duas primeiras décadas 
(McCOMBS; SHAW, 2000b). Dois anos após a publicação do artigo inaugural, Weaver, McCombs e Spellman analisam 0 agendamento do caso Watergate e explicam o agendamento como uma

[...] acentuada relação positiva entre as ênfases da cobertura mediática e a importância assumida por esses assuntos para os indivíduos que compõem o público. Mais, esse princípio é formulado em termos causais: a saliência acrescida de um assunto nos media provoca 0 aumento da importância desse assunto na consciência das pessoas (WEAVER; McCOMBS; SPELLMAN, 2000, p. 65).

0 crescimento numérico deu forças ao agendamento. Segundo Traquina, ultrapassase 0 conceito inicial que limitava a influência da agenda jornalística sobre agenda pública à simples saliência das questões e ocorrências que tinham merecido destaque como notícia. A metodologia proposta na fase inicial incluía a análise de conteúdo dos veículos e um estudo com o público, confrontando a pauta veiculada pela imprensa com a formação da agenda pública. Contudo, na evolução das pesquisas, outros enfoques e desdobramentos surgiram.

Enquanto as fases iniciais da pesquisa sobre 0 agendamento se concentravam na questão "Quem determina a agenda pública - e em que condições?", a mais recente fase de trabaIho centrou a sua atenção na pergunta "Quem determina a agenda dos media?" (McCOMBS; SHAW, 2000b, p. 128).

Conforme McCombs e Shaw (2000b), os estudos de agenda-setting se desdobram em quatro fases. Na fase inicial, os trabalhos acadêmicos reivindicando o AS focaram nas relações entre a agenda da mídia e a agenda do público. A segunda fase, que aparece em 1977, busca entender as condições que intensificavam ou limitavam a formação da agenda do público, chegando a conceitos como a necessidade de orientação do público, hierarquia entre os temas e características de cada suporte midiático. A terceira frente é voltada para pesquisas sobre a cobertura das campanhas eleitorais, examinando a agenda dos candidatos e a sua apreensão pelo público. Foi nos anos 1980 que os estudos entram na sua quarta fase e se voltam para as fontes das agendas midiáticas.

Embora os autores iniciais elenquem quatro fases, foi a perspectiva inicial do agenda-setting que funcionou como um guarda-chuva para um conjunto de investigações e novos conceitos, todos eles perpassados em alguma medida pela ideia de "poder da mídia". Contra-argumentando Cohen, os fundadores chegaram a concluir:

0 agendamento é bastante mais do que a clássica asserção de que as notícias nos dizem sobre 0 que é que devemos pensar. As notícias dizem-nos também como devemos pensar sobre 0 que pensamos. Tanto a selecção de objectos para atrair a atenção como a selecção de enquadramentos para pensar sobre esses objectos são tarefas poderosas do agendamento (McCOMBS; SHAW, 2000b, p. 131).

\section{0 agenda-setting no Brasil}

Em particular no Brasil, a temática do agendasetting (ou do agendamento, quando traduzido) 
ganhou espaço a partir da década de 1990, especialmente com trabalhos publicados em Portugal ou por portugueses no Brasil, como o livro Teorias da comunicação, do italiano Mauro Wolf, e Poder do Jornalismo e 0 estudo do jornalismo no século XX, de Nelson Traquina, e por brasileiros, como Ética da Comunicação, de Clovis Barros Filho, e de artigos em periódicos e capítulos de livros (HOHLFELDT, 1997; TRAQUINA, 2000; AZEVEDO, 2004). A partir da publicação de obras ou artigos em português, que facilitaram a questão do idioma e até mesmo 0 acesso à abordagem, 0 AS foi disseminado no Brasil. Na nossa pesquisa, não conseguimos detectar nenhum trabalho brasileiro anterior aos artigos de Traquina, publicado em 1995, e de Hohlfeldt (1997).

Observando os três grandes eventos das ciências da comunicação no Brasil - Intercom, Compós e SBPJor -, identificamos 34 trabalhos apresentados nos últimos cinco anos (20052009) que em sua abordagem faziam referência aos termos agenda-setting ou agendamento da mídia (no corpo do trabalho, estando entre as palavras-chave ou não). A grande maioria das abordagens (53\%) trata especificamente da agenda da mídia, aquilo que seria apontado por McCombs e Shaw (2000b) como a quarta fase dos estudos inspirados na hipótese fundadora. 0 caminho seguido pelos pesquisadores brasileiros se direciona para a tentativa de explicar como os media pautam certos acontecimentos, invariavelmente retornando à defesa de que os meios de comunicação determinam não somente o que pensar, mas como devemos pensar. Mesmo os trabalhos que relativizam a posição da audiência, indicando um receptor não completamente passivo e admitindo outras variáveis sociais e psicológicas, recaem na relação entre causa e efeito e concluem quase que por obviedade que a mídia, ao pautar e enquadrar os assuntos, tem sim o poder de definir a agenda do público.

Cada vez mais, a hipótese (por vezes tratada como teoria, outras como conceito) é somada aos estudos relativos à rotina jornalística e a produção das notícias, o newsmaking e seus critérios de noticiabilidade, além de considerar o papel do gatekeeper e até mesmo a espiral do silêncio como reflexo do poder da imprensa em pautar ou calar determinados temas na sociedade. A abordagem de cerca de $15 \%$ dos artigos coletados partem da hipótese central e direta de que a mídia influencia a agenda do público e outros 15\%, ao contrário, atestam o poder das fontes, ou 0 chamado contra-agendamento, analisando o papel das assessorias de imprensa, das organizações civis ou da esfera política em pautar os veículos. Há ainda um percentual aproximado de $9 \%$ em que se discutiram as inter-influências entre as agendas da mídia e da política.

Apesar de volume tão alto considerar a influência da agenda da mídia sobre os temas que estão na agenda do dia, da sociedade, nenhum trabalho realizou qualquer tipo de análise junto 
à audiência ou recepção. Aproximadamente $59 \%$ adotaram como metodologia a análise de conteúdo, comparando trechos, manchetes ou reportagens de veículos impressos ou eletrônicos (televisão e internet). Assim, analisa-se 0 produto do jornalismo - a notícia; em geral se discutem os processos de construção da pauta e seu enquadramento e se conclui que, ao dar determinada abordagem a um assunto, será esta visão que a audiência irá absorver e assumir. A hipótese, inicialmente um compilado de proposições a serem testadas, é tomada como verdade. Quase $15 \%$ das pesquisas realizaram algum tipo de estudo de caso, e cerca de 18\% realizaram a revisão bibliográfica, abordando 0 histórico do agendamento e possíveis interrelações com outros conceitos ou correntes teóricas.

Em relação às fontes de referência teórica, menos da metade (44\%) recorreram aos diretamente aos fundadores, trabalhando com os escritos de McCombs e Shaw. Ainda assim, os que citam os autores, buscaram as informações no artigo inicial (de 1972), sem acompanhar o que os investigadores iniciais e outros desenvolveram nos 40 anos que decorreram após terem lançado 0 conceito do agenda-setting. No caso dos artigos brasileiros selecionados neste levantamento, aproximadamente $60 \%$ se referenciam nos textos de autoria ou traduzidos por Nelson Traquina. 47\% também citam Mauro Wolf em seu livro Teorias da Comunicação, lançado originalmente em 1985, com primeira versão em português datada de 1987. Poucos trabalhos apresentados nesses eventos citam outros artigos que utilizaram o mesmo referencial teórico ou que reivindicam da mesma metodologia. Uma rara exceção é 0 artigo de Barbosa e Aguiar (2009), que cita pelo menos seis trabalhos sobre 0 agendamento. Apesar do expressivo número de trabalhos sobre o AS ou sobre 0 agendamento, inexiste uma acumulação de conhecimento.

Além disso, ainda que utilizem a terminologia "agendamento", alguns trabalhos se ancoram em outras tradições de pesquisa ou fazem uso de referências teóricas distintas do AS. A confusão epistemológica e metodológica não é exclusividade dos estudos sobre agenda-setting. Porto (2004) mostra as fragilidades dos estudos sobre 0 enquadramento. Já algumas pesquisas mais recentes, que se dedicam à construção da agenda da mídia, passam a adotar novas terminologias, como 0 agenda-building, por, mesmo ancoradas na proposta inicial através da citação bibliográfica, distanciarem-se do conceito-chave da hipótese do AS. Por outro lado, apropriações simplificadas do tema do agendamento também contribuíram para estudos essencialmente embasados em análises de conteúdo, desconsiderando uma parte importante para a confirmação de tais hipóteses, como características interpessoais e intra-pessoais (WOLF, 1999), fatores psicológicos e sociológicos na recepção e, acima de tudo, uma variabilidade de mediações que não estão restritas aos meios de comunicação.

Desde o final dos anos 1990, quando os primeiros estudos com o enfoque do agendamento começaram 
a ser desenvolvidos no país, o que prevaleceu foi a quarta fase, que tratou mais da agenda midiática, do que das relações investigadas com o que estava na agenda da sociedade, e como a mídia influencia a agenda da sociedade. Os estudos de audiência foram preteridos ou negligenciados nessa abordagem. 0 risco mais imediato disso é o desvio daquilo que deveria ser uma "hipótese", que passou a ser tratada como certeza, uma lógica imediata: tal veículo priorizou tal candidato, logo o público foi diretamente influenciado a decidir a favor dele nas eleições.

0 agenda-setting ganhou destaque no Brasil no período em que o país viveu a abertura política e 0 crescente papel da imprensa nos debates públicos, desde a campanha das "Diretas Já" até a primeira eleição direta para presidente e seu posterior impeachment. 0 crescimento do papel da mídia na sociedade contemporânea, especialmente após 0 processo de abertura política, e a busca constante por reforços que justificassem 0 "poder da imprensa" podem ser apontados como fatores para a utilização dessa abordagem entre pesquisadores brasileiros. A vitória de Fernando Collor de Mello, nas eleições de 1989, bem como a reeleição de Fernando Henrique Cardoso em 1998, por exemplo, foram apontadas por jornalistas e estudiosos da área como evidência do poder de mídia de influenciar a sociedade (CONTI, 1999; AZEVEDO, 2000).

\section{Considerações finais}

No livro sobre a evolução das teorias da comunicação, Armand e Michèle Mattellart (1995) constatam que 0 esquema de comunicação definido por Harold Lasswell, no final da década de 1940, teve como decorrência 0 fato dos pesquisadores em comunicação terem concentrado suas atenções para um desses tópicos, privilegiando a análise do "Diz o quê" (Análise de conteúdo) e "Com que efeito" (Análise dos efeitos). Força é de admitir que, ainda que tenha, a partir da década de 1970, ampliado os objetos e as abordagens, a pesquisa em comunicação continua a ressentir de uma primazia dos estudos sobre 0 conteúdo e 0 efeito das mídias. Pior, muitos pesquisadores se concentram na análise do conteúdo e, a partir do resultado, deduzem que o público pode ter feito a mesma leitura sugerida pelo produtor da mensagem. Ou seja, o público absorve a mensagem sem nenhuma reação num processo comunicativo considerado linear e em que cada mensagem é capaz de surtir um efeito discernível e identificável. Várias sequências de estudos, de diversas epistemologias, tradições e referenciais teóricos desmontaram, superaram, modificaram essa abordagem da maneira como o público se relaciona com a mensagem midiática. Entretanto, a atração que essa tradição exerce sobre os pesquisadores em comunicação é visível e se assemelha a um movimento pendular que traz 0 constante retorno da questão do "efeito" da mídia sobre as pessoas. Essa tradição de pesquisas que 
centra suas atenções no "efeito" causado pela mídia ainda tem seus seguidores. 0 sucesso do paradigma do agendamento no Brasil revela como a identificação de um efeito palpável e discernível e um amplo poder da mídia sobre as pessoas ainda assombram as mentes e os corações da academia.

Essa primazia dos estudos sobre conteúdo, com conclusões sobre um suposto efeito das mídias, pode estar relacionada com as peculiaridades das pesquisas em Jornalismo. Silva e Pontes (2009) analisam os impasses para uma Teoria do Jornalismo, com dois campos de análise que se opõem: um que não considera que haja qualquer particularidade epistemológica ao jornalismo para a construção de uma teoria desassociada de outros campos; e outra que entende o jornalismo como um setor autônomo, tomando por objeto da teoria as práticas profissionais, os produtos e processos das empresas de comunicação.

A estratégia mais comum e, logo, hegemônica nesse processo, é a que localiza o objeto de estudo do Jornalismo exclusivamente na investigação de seu produto material, no caso, 0 jornal, a revista, o telejornal, o radiojornal e os sítios de notícias. A manifestação empírica do objeto é tomada pelo próprio objeto, enclausurando uma possível Teoria do Jornalismo nas Teorias da Notícia, identificadas como teorias circunscritas às técnicas, processos e produtos da rotina profissional do jornalista (SILVA; PONTES, 2009, p. 177).

As abordagens excessivas sobre 0 agendamento, especialmente com apropriações simplificadas, alimentam a pouca tradição brasileiros em estudos de recepção e sobressaem pesquisas que se contentam com o caráter descritivo e em apenas detalhar como as notícias são construídas. Trata-se de um midiacentrismo exacerbado nos estudos brasileiros da comunicação, com investigações que "mergulham tanto nos conteúdos analisados que dificilmente retornam às reflexões sobre o Jornalismo" (SILVA; PONTES, 2009, p. 181).

Ao restringir sua análise sobre o produto jornalístico, dotado de uma materialidade e com dimensões temporais e espaciais definidas, 0 pesquisador facilita seu trabalho. Entretanto, apesar das suas fragilidades conceituais, epistemológicas e metodológicas, 0 agendasetting tinha uma virtude de se interessar ao mesmo tempo pelo produto final do jornalismo e pela audiência do produto jornalístico. Apesar da abordagem restritiva e da relação causal, faz parte do paradigma a verificação sincrônica da mídia e do público. Ora, movendo-se para o enquadramento, que no Brasil continua privilegiando a análise do produto jornalístico e os poucos trabalhos sobre o público focam no "efeito" do enquadramento sobre a recepção. Movendo para 0 agenda-building, corre-se 0 risco ainda maior de ressaltar na Teoria do Jornalismo apenas a Teoria da Notícia, e se ater às questões "por que as notícias são o que são", considerando como sinônimos Teoria do Jornalismo e Teoria da Notícia. Ao fazê-lo, "toma-se, metonimicamente, parte do objeto do Jornalismo como todo o objeto da Teoria do Jornalismo. Desse modo, dribla-se 
a insegurança teórica fixando-se na empiria do mundo prático da profissão, na expectativa de que a materialidade dos produtos e processos jornalísticos responda naturalmente pela teoria" (SILVA, 2009).

Wolf (1999) inclui os critérios relativos ao público entre aos valores/notícias, que formam a noticiabilidade de um acontecimento ou assunto. Nesse item, o autor discute como a representação que os jornalistas têm do público influencia a seleção e 0 tratamento da informação. Segundo ele, os jornalistas ressentem que levar em consideração as preferências do público pode ser um estorvo para a produção da notícia e equacionam a tensão entre 0 interesse do público e a autonomia profissional de definição do que é notícia. Entretanto, "o termo de referência constituído pelo público - o melhor, pelas opiniões que os jornalistas têm acerca do público - e os limites dessa referência, são um dos aspectos mais interessantes e menos aprofundados da temática do newsmaking" (WOLF, 1999, p. 213). Essa constatação é partilhada por Neveu (2006), que afirma que 0 público é um personagem ausente nos trabalhos sobre o jornalismo que em muitos casos só se tem uma representação intuitiva do público. Mesmo que de maneira parcelar, a metodologia adotada por McCombs e Shaw (2000a) volta sua atenção para o público, enquanto que as abordagens sucessoras se focam apenas na mídia de informação.
0 desafio maior não é compreender se 0 agenda-setting pertence ou não à tradição dos efeitos limitados, ou se os estudos subseqüentes - como 0 agenda-building ou 0 enquadramento - são aprimoramentos, superação ou evolução do AS. Ao reter a atenção sobre o processo de produção da notícia, sobre a noticiabilidade dos acontecimentos e temas, os pesquisadores alimentam uma visão midiacêntrica. A consequência é que o objeto teórico da comunicação, quando é um mero reflexo das práticas de mídia, fica sem qualquer objeto próprio. Muniz Sodré (2008) considera que os estudos de comunicação que se reduzem a analisar e descrever a pura interação entre pessoas mediada pela mídia deixam subjacente uma afirmação "como natural, politicamente intocável e cientificamente garantido um modelo de sociedade fragmentada, constituída de indivíduos competitivos e isolados dispostos numa rede hipertecnológica e midiaticamente relacionados" (SODRÉ, 2008, p. 223).

A fragmentação das pesquisas sobre a agenda-setting em uma das suas vertentes (agendamento da mídia pelas fontes; agenda da mídia; agendamento do público pela mídia) acarreta um isolamento dos elementos que fazem parte do processo comunicativo. Estudase a fonte de informação e sua incidência sobre a mídia ou as rotinas de produção da notícia ou a correlação causal entre a agenda da mídia e a agenda do público. 0 corolário é que as 
pesquisas derivadas dessa tradição de pesquisa ou que se servem da sua metodologia ou de seu referencial teórico fazem economia das condições sociais de produção do sentido, deixando de discutir como se "articula" o sentido de uma sociedade. Ocupa-se apenas da transmissão e da mediação de informações, e restringe o processo comunicativo a um eixo linear que pode ser resumido no esquema emissor/mensagem/receptor. Barbero combate ferozmente essa fragmentação:

Essa fragmentação equipara o processo de comunicação ao de transmissão de uma informação ou, melhor dizendo, reduz aquele a este. Daí se converter em verdade metodológica a separação entre a análise da mensagem - seja uma análise de conteúdo ou de expressão, de estruturas textuais ou operações discursivas - e a análise da recepção concebida simples ou sofisticadamente como indagação acerca dos efeitos e da reação (MARTÍN-BARBER0, 2003, p. 293).

Em um artigo no qual faz um levantamento sobre evolução da pesquisa em Jornalismo no Brasil, Machado (2004) enumera as principais linhas de pesquisa desenvolvidas desde os anos 1970, quando sugiram os primeiros programas de pós-graduação no Brasil. São elas: História do Jornalismo, Teorias do Jornalismo, Análise do discurso, Produção da Notícia, Recepção, Jornalismo Especializado, Jornalismo Digital e Teorias da Narrativa. Nessa categorização proposta por Machado, podemos discernir uma fragmentação das linhas de pesquisas que podem resultar num isolamento da investigação sobre a mensagem e a recepção.

\section{Referências}

AGUIAR, Sonia. Jornalismo hipermídia na divulgação científica: experiências e lacunas nos sites de universidades públicas e fundações de apoio à pesquisa do Nordeste. In: CONGRESSO BRASILEIRO DE CIÊNCIAS DA COMUNICAÇÃO, 32., 2009, Curitiba. Anais... Curitiba: Intercom, 2009. CD-ROM.

ARAÚJO NETO, Jefferson Garrido de. Estratégias Teóricas de Midiatização e Agendamento do Discurso Científico. In: CONGRESSO BRASILEIRO DE CIÊNCIAS DA COMUNICAÇÃO, 32., 2009, Curitiba. Anais... Curitiba: Intercom, 2009. CD-ROM.

AZEVED0, Nisia Rizzo de. Por que caminhos metodológicos trafegam as críticas dos observatórios de mídia? In: ENCONTRO NACIONAL DE PESQUISADORES EM JORNALISMO, 7., 2009, São Paulo. Anais... São Paulo: SBPJor, 2009. CD-ROM. AZEVED0, Fernando Antônio. A agenda da mídia na campanha presidencial de 1998. In: ENCONTRO NACIONAL DA COMPÓS, 9., 2000, Porto Alegre. Anais... Porto Alegre: Compós, 2000. CD-ROM. Agendamento da política. In: RUBIM, Antonio Albino Canelas (org.). Comunicação e política: conceitos e abordagens. Salvador: UFBA; São Paulo: Unesp, 2004. p. 41- 71.

BARBOSA, Suzana; AGUIAR, Sonia. Bases de dados jornalísticas e perspectivas de agendamento na web regional. In: ENCONTRO NACIONAL DE PESQUISADORES EM JORNALISMO, 8., 2009, São Paulo. Anais... São Paulo: SBPJor, 2009. CD-ROM.

BARROS FILHO, Clóvis. Ética na comunicação. São Paulo: Summus, 1995.

BECKER, Beatriz; VIANA, Taisa G.; LIMA, Marcos. TJUFRJ: uma reflexão crítica e uma experiência empírica sobre o Jornalismo audiovisual na web. In: CONGRESSO BRASILEIRO DE CIÊNCIAS DA COMUNICAÇÃO, 30., 2007, Santos. Anais... Santos: Intercom, 2007. CD-ROM. 
Essas reportagens são muito

legais! Por quê? In: ENCONTRO NACIONAL DE PESQUISADORES EM JORNALISMO, 5., 2007, Aracaju. Anais... Aracaju: SBPJor, 2007. CD-ROM.

BECKER, Gisele. A construção da imagem da prostituição e da moralidade em Porto Alegre pelo jornal A Gazetinha: uma análise dos códigos sociais através da Hipótese de Agendamento (1895-1897). In: CONGRESSO BRASILEIRO DE CIÊNCIAS DA COMUNICAÇÃO, 30., 2007, Santos. Anais... Santos: Intercom, 2007. CD-ROM.

BONFIM, Willian Silva. A agenda das fontes e a agenda jornalística. In: ENCONTRO NACIONAL DE PESQUISADORES EM JORNALISMO, 3., 2005, Florianópolis. Anais... Florianópolis: SBPJor, 2005. CD-ROM.

CANELA, Guilherme. Mídia e políticas públicas de comunicação: uma análise empírica da imprensa brasileira. In: CONGRESSO BRASILEIRO DE CIÊNCIAS DA COMUNICAÇÃO, 30., 2007, Santos. Anais... Santos: Intercom, 2007. CD-ROM.

CANELA, Guilherme. Quem guarda o guardião: quando o observador, observa a si mesmo. In: ENCONTRO NACIONAL DE PESQUISADORES EM JORNALISMO, 4., 2006, Porto Alegre. Anais... Porto Alegre: Intercom, 2006. CD-ROM.

CELESTINO, Mônica. Notícias do Brasil e do mundo no jornal regional: a agenda das editorias Nacional e Internacional do jornal A Tarde. In: ENCONTRO NACIONAL DE PESQUISADORES EM JORNALISMO, 3., 2005, Florianópolis. Anais... Florianópolis: SBPJor, 2005. CD-ROM.

CHARRON, Jean. Les médias et les sources: les limites du modele de l'agenda-setting. Hermès, Paris, n. 17-18, p. $73-92,1995$.

COLLING, Leandro. Agenda-setting e framing: reafirmando os efeitos limitados. Revista FAMECOS, Porto Alegre, n. 14, p. 88-101, abr. 2001.
CONTI, Mário Sérgio. Notícias do Planalto. São Paulo: Cia das Letras, 1999.

DEPEXE, Sandra D.; AREU, Graciela I. P. Pautando o tele-vidente com a publicidade? Estudo de caso do Projeto de Lei 29/2007. In: CONGRESSO BRASILEIRO DE CIÊNCIAS DA COMUNICAÇÃO, 31., 2008, Natal. Anais... Natal: Intercom, 2008. CD-R0M.

DUARTE, Luiz A. F.; MÜLLER, Karla M. 0 poder da imprensa brasileira na Primeira República: uma análise preliminar sobre agendamento. In: ENCONTRO NACIONAL DE PESQUISADORES EM JORNALISMO, 4., 2006, Porto Alegre. Anais... Porto Alegre: SBPJor, 2006. CD-ROM.

FIGUEIRED0, Carlos. Agendando as eleições: 0 jornalismo e as imagens da política. In: CONGRESSO BRASILEIRO DE CIÊNCIAS DA COMUNICAÇÃO, 31., 2008, Natal. Anais... Natal: Intercom, 2008. CD-ROM.

GONÇALVES, Janayde de Castro. Agendamento e frames da questão climática nos impressos brasileiros. In: ENCONTRO NACIONAL DE PESQUISADORES EM JORNALISMO, 6., 2008, São Paulo. Anais... São Paulo: SBPJor, 2008. CD-ROM.

HOHLFELDT, Antonio. Os estudos sobre a hipótese de agendamento. Revista Famecos, Porto Alegre, n. 7, p. 42-51, nov. 1997.

LEAL, Bruno Souza. Reflexões sobre 0 agendamento: síntese de um estudo de caso. In: CONGRESSO BRASILEIRO DE CIÊNCIAS DA COMUNICAÇÃO, 32., 2009, Curitiba. Anais... Curitiba: Intercom, 2009. CD-ROM.

LIEDTKE, Paulo. Governando com a mídia: 0 agendamento mútuo entre o Estado e os mass media na política nacional. In: ENCONTRO NACIONAL DA COMPÓS, 16., 2007, Curitiba. Anais... Curitiba: Compós, 2007. CD-ROM.

Governando com a mídia: 0 agendamento e o enquadramento ao projeto de criação da Agência Nacional de Audiovisual (2004). In: CONGRESSO 
BRASILEIR0 DE CIÊNCIAS DA COMUNICAÇÃO, 31., 2008, Natal. Anais... Natal: Intercom, 2008. CD-ROM.

LIPPMANN, Walter. Opinião pública. Petrópolis: Vozes, 2008.

MACHAD0, Elias. Dos estudos sobre jornalismo às teorias do jornalismo (três pressupostos para a consolidação do jornalismo como campo de conhecimento). E-Compós, Brasília, v. 1, p. 2-15, dez. 2004.

MAGALHÃES, Caio C. M.; CARM0, Isabel P. S. X. As especificidades e possibilidades do intra-agendamento sob o viés do caso de Paula Oliveira. In: CONGRESSO BRASILEIRO DE CIÊNCIAS DA COMUNICAÇÃO, 32. 2009, Curitiba. Anais... Curitiba: Intercom, 2009. CD-ROM.

MARÔPO, Lidia Soraya Barreto. Movimentos de defesa da infância e a cobertura sobre educação pública. Um estudo empírico sobre a imprensa cearense. In: CONGRESSO BRASILEIRO DE CIÊNCIAS DA COMUNICAÇÃo, 29., 2006, Brasília. Anais... Brasília: Intercom, 2006. CD-ROM.

MARQUES, José C.; LOPES, Mayra C. A copa do mundo é nossa: a organização do mundial de futebol no Brasil em 2014 retratada pela imprensa nacional e europeia. In: CONGRESSO BRASILEIRO DE CIÊNCIAS DA COMUNICAÇÃo, 32., 2009, Curitiba. Anais... Curitiba: Intercom, 2009. CD-ROM.

MARTÍN-BARBER0, Jesús. Dos meios às mediações: comunicação, cultura e hegemonia. Rio de Janeiro: UFRJ, 2003.

MARTINO, L. C. Os cursos de teoria da comunicação à luz do jornalismo: obstáculos e impropriedades das posições tecnicista e intelectualista. In: FERREIRA, Giovandro Marcus; MARTINO, Luiz Claudio (org.). Teorias da comunicação: epistemologia, ensino, discurso e recepção. Salvador: EDUFBA, 2007.

MATTELART, Armand ; MATTELART, Michèle.
Histoire des théories de la communication. Paris: La Découverte, 1995.

MATTOSO, Diego. Politics, policy e o jornalismo político. In: ENCONTRO NACIONAL DE PESQUISADORES EM JORNALISMO, 6., 2008, São Paulo. Anais... São Paulo: SBPJor, 2008. CD-ROM. MAZZARINO, Jane. 0 agendamento na perspectiva das fontes do campo jornalístico: observando fazeres do movimento socioambiental. Revista Fronteiras, São Leopoldo, v. 9, n. 1, pág. 53-63, jan./abr. 2007. Disponível em: <http://revcom.portcom.intercom.org. br/index.php/fronteiras/article/viewFile/3155/2965>. Acesso em: 31 jan. 2011.

McCOMBS, Maxwell; SHAW, Donald. A função do agendamento dos media. In: TRAQUINA, Nelson. 0 poder do jornalismo: análise e textos da teoria do agendamento. Coimbra: Minerva, 2000a.

- A evolução da pesquisa sobre 0 agendamento: vinte e cinco anos no mercado das ideias. In: TRAQUINA, Nelson. 0 poder do jornalismo: análise e textos da teoria do agendamento. Coimbra: Minerva, 2000b.

MEL0, Paula Reis. A perspectiva da agenda-building e sua contribuição para o estudo das agendas política, midiática e pública. In: ENCONTRO NACIONAL DE PESQUISADORES EM JORNALISM0, 5., 2007, Aracaju. Anais... Aracaju: SBPJor, 2007. CD-ROM.

MOTA, Célia Ladeira. Discursos da periferia nas notícias locais da TV. In: ENCONTRO NACIONAL DE PESQUISADORES EM JORNALISM0, 5., 2007, Aracaju. Anais... Aracaju: SBPJor, 2007. CD-ROM.

NISBET, Matthew C. Agenda building. The International Encyclopedia of Communication, 2008. Disponível em: http://147.9.1.95/docs/agenda.pdf. Acesso em: 15 mai. 2010.

NEVEU, Érik. Sociologia do jornalismo. São Paulo: Loyola, 2006.

OLIVEIRA, Maria de Fátima Costa de. Imprensa e controle social: um Estado de Poder. In: CONGRESSO 
BRASILEIRO DE CIÊNCIAS DA COMUNICAÇÃ0, 29., 2006, Brasília. Anais... Brasília: Intercom, 2006. CD-ROM.

OLIVEIRA, Rodrigo B.; BARRETO, Betânia M. V. B.; SOUSA, Anaelson L. de. Comunicação e meio ambiente: a divulgação da Agenda 21 em Vitória da Conquista, Bahia. In: ENCONTRO NACIONAL DE PESQUISADORES EM JORNALISMO, 3., 2005, Florianópolis. Anais... Florianópolis: SBPJor, 2005. CD-ROM.

PAULIN, Bruna do Amaral. A Beatlemania nos EUA: agendamento ou acontecimento midiático? In: CONGRESSO BRASILEIRO DE CIÊNCIAS DA COMUNICAÇÃO, 32., 2009, Curitiba. Anais... Curitiba: Intercom, 2009. CD-ROM.

PORTO, Mauro P. Enquadramentos da mídia e política. In: RUBIM, Antonio Albino Canelas (org.). Comunicação e política: conceitos e abordagens. Salvador: UFBA; São Paulo: Unesp, 2004. p. 73- 104. QIU, Qi; CAMERON, Glen. Building a media agenda on prosocial causes: how issue perceptions and news values work to influence effectiveness. International Communication Association. Dresden, 2006.

Disponível em: <http://www.allacademic.com/meta/ p93166_index.html>. Acesso em: 15 mai. 2010.

RAUSCH, Fábio. 0 caso Kliemann e a hipótese do agendamento entre o Diário de Notícias e a Última Hora. In: CONGRESSO BRASILEIRO DE CIÊNCIAS DA COMUNICAÇÃO, 32., 2009, Curitiba. Anais... Curitiba: Intercom, 2009. CD-ROM.

SALLET, Beatriz. Histórias e 'estórias' fotográficas: um estudo sobre a produção fotojornalística do jornal impresso diário Zero Hora. In: ENCONTRO NACIONAL DE PESQUISADORES EM JORNALISMO, 4., 2006, Porto Alegre. Anais... Porto Alegre: SBPJor, 2006. CD-ROM.

SILVA, Jan A. B. E. Considerações iniciais sobre 0 modelo de agenda-setting aplicado à personalização da informação na blogosfera. In: ENCONTRO NACIONAL DE PESQUISADORES EM JORNALISMO, 4., 2006, Porto Alegre. Anais... Porto Alegre: SBPJor, 2006. CD-ROM.

SILVA, Jan Alyne Souza e. Reflexões metodológicas sobre o estudo do agenda-setting no sistema de promoção de notícias Menéame. In: ENCONTRO NACIONAL DE PESQUISADORES EM JORNALISMO, 6., 2008, São Paulo. Anais... São Paulo: SBPJor, 2008. CD-ROM.

SILVA, Luiz Martins da. Sociedade, esfera pública e agendamento. In: LAGO, Cláudia; BENETTI, Márcia. Metodologia de pesquisa em jornalismo. Petrópolis: Vozes, 2007. p. 84-104.

SILVA, Gislene. Sobre a imaterialidade do objeto de estudo do Jornalismo. E-Compós, Brasília, v.12, n.2, maio/ago. 2009. Disponível em: <http://www. compos.org.br/seer/index.php/e-compos/article/ viewFile/372/357>. Acesso em: 31 jan. 2011. ; PONTES, Felipe. Teorias da notícia: impasses para a Teoria do Jornalismo. Revista Fronteiras, São Leopoldo, v. 11, n. 3, p. 176-184, set./ dez. 2009. Disponível em: <http://www.fronteiras. unisinos.br/pdf/76.pdf>. Aceso em: 31 jan. 2011.

SODRÉ, Muniz. Antropológica do espelho: uma teoria da comunicação linear e em rede. Petrópolis: Vozes, 2008.

SOARES, Valéria Deluca. A agenda setting e a comunicação nas organizações: um encontro possível. In: CONGRESSO BRASILEIRO DE CIÊNCIAS DA COMUNICAÇÃO, 30., 2007, Santos. Anais... Santos: Intercom, 2007. CD-ROM.

TRAQUINA, Nelson. 0 poder do jornalismo: análise e textos da teoria do agendamento. Coimbra: Minerva, 2000.

URIARTE, Urpi M.; BROTAS, Antônio M. P. 0 predomínio do enquadramento político-nacionalista na cobertura da nacionalização do gás natural da Bolívia. In: ENCONTRO NACIONAL DE PESQUISADORES EM 
JORNALISMO, 4., 2006, Porto Alegre. Anais... Porto Alegre: SBPJor, 2006. CD-ROM.

VAZ, Paulo B.; ANTUNES, Elton. Acontecimentos e homofobia: considerações sobre agendamento, noticiabilidade e enquadramento. In: ENCONTRO NACIONAL DE PESQUISADORES EM JORNALISMO, 7., 2009, São Paulo. Anais... São Paulo: SBPJor, 2009. CD-ROM.

WEAVER, David H.; McCOMBS, Maxwell; SPELLMAN, Charles. Watergate e os media. In: TRAQUINA, Nelson. 0 poder do jornalismo: análise e textos da teoria do agendamento. Coimbra: Minerva, 2000.

WOLF, Mauro. Teorias da comunicação. 5. ed. Lisboa: Presença, 1999.

ZHU, Jian-Hua; BLOOD, Deborah. Media agendasetting theory: review of a 25-year research tradition. Perspectives, Hong Kong, v.8, p. 97-149, 1996. Disponível em: http://sunzi.lib.hku.hk/hkjo/ view/10/1000100.pdf. Acesso em: 15 mai. 2010. 


\begin{tabular}{|c|c|}
\hline $\begin{array}{l}\text { Agenda-setting in Brazil: the } \\
\text { contradictions between success } \\
\text { and epistemological limits }\end{array}$ & $\begin{array}{l}\text { El agenda-setting en Brasil: las } \\
\text { contradicciones entre el éxito y } \\
\text { los límites epistemológicos }\end{array}$ \\
\hline $\begin{array}{l}\text { Abstract: } \\
\text { Within the context of emerging journalism studies, } \\
\text { the regular criticism and successive efforts to } \\
\text { determine the epistemological and methodological } \\
\text { field boundaries, this paper inquires the agenda- } \\
\text { setting and its nationwide successful approach. } \\
\text { Starting with an empirical survey based on papers } \\
\text { presented at the main Brazilian communication } \\
\text { studies forums, we look analyze how Brazilian } \\
\text { researchers reframe this traditional address, } \\
\text { including the body of methodologies and the } \\
\text { knowledge accumulation. } \\
\text { Keywords: } \\
\text { Agenda-setting. Theory of Journalism. } \\
\text { Communication Epistemology. }\end{array}$ & $\begin{array}{l}\text { Resumen: } \\
\text { Con el florecimiento de los estudios de periodismo, } \\
\text { la frecuente crítica y los sucesivos esfuerzos } \\
\text { por delimitar el área epistemológicamente y } \\
\text { metodológicamente, este estudio pone en cuestión } \\
\text { la agenda-setting, y el éxito del enfoque alcanzado } \\
\text { en Brasil. Desde una mirada empírica, basada en } \\
\text { trabajos presentados en los principales foros de } \\
\text { ciencias de la comunicación en Brasil, analizamos } \\
\text { como la influencia de esta tradición es reapropiada } \\
\text { por los investigadores brasileños, incluyendo } \\
\text { las metodologías utilizadas y la acumulación de } \\
\text { conocimiento. } \\
\text { Palabras clave: } \\
\text { Agenda-setting. Teoría del Periodismo. } \\
\text { Epistemología de la Comunicación. }\end{array}$ \\
\hline
\end{tabular}




\section{Expediente}

A revista E-Compós é a publicação científica em formato eletrônico da Associação Nacional dos Programas de Pós-Graduação em Comunicação (Compós). Lançada em 2004, tem como principal finalidade difundir a produção acadêmica de pesquisadores da área de Comunicação, inseridos em instituições do Brasil e do exterior.
E-COMPÓS I www.e-compos.org.br I E-ISSN 1808-2599

Revista da Associação Nacional dos Programas de Pós-Graduação em Comunicação. Brasília, v.13, n.3, set./dez. 2010.

A identificação das edições, a partir de 2008 passa a ser volume anual com três números.

\section{CONSELHO EDITORIAL}

Afonso Albuquerque

Universidade Federal Fluminense, Brasil

Alberto Carlos Augusto Klein

Universidade Estadual de Londrina, Brasi

Alex Fernando Teixeira Primo

Universidade Federal do Rio Grande do Sul, Brasil

Alfredo Vizeu

Universidade Federal de Pernambuco, Brasi

Ana Carolina Damboriarena Escosteguy

Pontifícia Universidade Católica do Rio Grande do Sul, Brasil

Ana Silvia Lopes Davi Médola

Universidade Estadual Paulista, Brasil

André Luiz Martins Lemos

Universidade Federal da Bahia, Brasil

Ângela Freire Prysthon

Universidade Federal de Pernambuco, Brasil

Antônio Fausto Neto

Universidade do Vale do Rio dos Sinos, Brasil

Antonio Carlos Hohlfeldt

Pontifícia Universidade Católica do Rio Grande do Sul, Brasil

Arlindo Ribeiro Machado

Universidade de São Paulo, Brasil

César Geraldo Guimarães

Universidade Federal de Minas Gerais, Brasil

Cristiane Freitas Gutfreind

Pontifícia Universidade Católica do Rio Grande do Sul, Brasil

Denilson Lopes

Universidade Federal do Rio de Janeiro, Brasil

Eduardo Peñuela Cañizal

Universidade Paulista, Brasil

Erick Felinto de Oliveira

Universidade do Estado do Rio de Janeiro, Brasil

Francisco Menezes Martins

Universidade Tuiuti do Paraná, Brasil

Gelson Santana

Universidade Anhembi/Morumbi, Brasil

Goiamérico Felício

Universidade Federal de Goiás, Brasil

Hector Ospina

Universidad de Manizales, Colômbia

Herom Vargas

Universidade Municipal de São Caetano do Sul, Brasil

leda Tucherman

Universidade Federal do Rio de Janeiro, Brasil

Itania Maria Mota Gomes

Universidade Federal da Bahia, Brasil

Janice Caiafa

Universidade Federal do Rio de Janeiro, Brasil

Jeder Silveira Janotti Junior

Universidade Federal da Bahia, Brasil

\section{João Freire Filho}

Universidade Federal do Rio de Janeiro, Brasil

John DH Downing

University of Texas at Austin, Estados Unidos

José Luiz Aidar Prado

Pontifícia Universidade Católica de São Paulo, Brasil

José Luiz Warren Jardim Gomes Braga

Universidade do Vale do Rio dos Sinos, Brasi

Juremir Machado da Silva

Pontifícia Universidade Católica do Rio Grande do Sul, Brasil

Lorraine Leu

University of Bristol, Grã-Bretanha

Luiz Claudio Martino

Universidade de Brasília, Brasil

Maria Immacolata Vassallo de Lopes

Universidade de São Paulo, Brasil

Maria Lucia Santaella

Pontifícia Universidade Católica de São Paulo, Brasil

Mauro Pereira Porto

Tulane University, Estados Unidos

Muniz Sodre de Araujo Cabral

Universidade Federal do Rio de Janeiro, Brasil

Nilda Aparecida Jacks

Universidade Federal do Rio Grande do Sul, Brasil

Paulo Roberto Gibaldi Vaz

Universidade Federal do Rio de Janeiro, Brasil

Renato Cordeiro Gomes

Pontifícia Universidade Católica do Rio de Janeiro, Brasil

Ronaldo George Helal

Universidade do Estado do Rio de Janeiro, Brasil

Rosana de Lima Soares

Universidade de São Paulo, Brasil

Rossana Reguillo

Instituto Tecnológico y de Estudios Superiores do Occidente, México

Rousiley Celi Moreira Maia

Universidade Federal de Minas Gerais, Brasil

Samuel Paiva

Universidade Federal de São Carlos, Brasil

Sebastião Albano

Universidade Federal do Rio Grande do Norte, Brasil

Sebastião Carlos de Morais Squirra

Universidade Metodista de São Paulo, Brasil

Simone Maria Andrade Pereira de Sá

Universidade Federal Fluminense, Brasi

Suzete Venturelli

Universidade de Brasília, Brasil

Valério Cruz Brittos

Universidade do Vale do Rio dos Sinos, Brasil

Veneza Mayora Ronsini

Universidade Federal de Santa Maria, Brasil

Vera Regina Veiga França

Universidade Federal de Minas Gerais, Brasil

\section{COMISSÃO EDITORIAL}

Felipe da Costa Trotta I Universidade Federal de Pernambuco, Brasi Rose Melo Rocha I Escola Superior de Propaganda e Marketing, Brasil Adriana Braga I Pontifícia Universidade Católica do Rio de Janeiro, Brasil

\section{CONSULTORES AD HOC}

Virginia Pradelina da Silveira Fonseca I Universidade Federal do Rio Grande do Norte, Brasi Christa Liselote Berger I Universidade do Vale do Rio dos Sinos, Brasi Márcia Benetti I Universidade Federal do Rio Grande do Sul, Brasil Tattiana Gonçalves Teixeira I Universidade Federal de Santa Catarina, Brasil

Gislene da Silva I Universidade Federal de Santa Catarina, Brasil José Afonso Junior I Universidade Federal de Pernambuco, Brasil EDIÇÃO DE TEXTO E RESUMOS I Everton Cardoso

TRADUÇÕES PARA O INGLÊS I Sieni Campos, Lisa Earl Castillo e Sabrina Glendhill EDITORAÇ̃̃ ELETRÔNICA I Roka Estúdio
COMPOS I wWw.compos.org.br

Associação Nacional dos Programas de Pós-Graduação em Comunicação

Presidente

Itania Maria Mota Gomes

Universidade Federal da Bahia, Brasil

itania@ufba.br

Vice-presidente

Julio Pinto

Pontifícia Universidade Católica de Minas Gerais, Brasil juliopinto@pucminas.br

Secretária-Geral

Ana Carolina Escosteguy

Pontifícia Universidade Católica do Rio Grande do Sul, Brasil carolad@pucrs.br 